\title{
Trends in childhood type 1 diabetes incidence in Europe during 1989-2008: evidence of non-uniformity over time in rates of increase
}

\author{
C. C. Patterson • E. Gyürüs • J. Rosenbauer • O. Cinek • A. Neu • \\ E. Schober • R. C. Parslow • G. Joner • J. Svensson • C. Castell • \\ P. J. Bingley • E. Schoenle • P. Jarosz-Chobot • B. Urbonaité • U. Rothe • \\ C. Krzisnik - C. Ionescu-Tirgoviste - I. Weets - M. Kocova - G. Stipancic • \\ M. Samardzic • C. E. de Beaufort • A Green • G. G. Dahlquist • G. Soltész
}

Received: 30 December 2011 / Accepted: 2 April 2012 /Published online: 26 May 2012

(C) Springer-Verlag 2012

\begin{abstract}
Aims/hypothesis The aim of the study was to describe 20year incidence trends for childhood type 1 diabetes in 23 EURODIAB centres and compare rates of increase in the first (1989-1998) and second (1999-2008) halves of the period. Methods All registers operate in geographically defined regions and are based on a clinical diagnosis. Completeness of registration is assessed by capture-recapture methodology.
\end{abstract}

Electronic supplementary material The online version of this article (doi:10.1007/s00125-012-2571-8) contains peer-reviewed but unedited supplementary material, which is available to authorised users.

C. C. Patterson $(\bowtie)$

Centre for Public Health, Queen's University Belfast, Institute of Clinical Science Block B, Grosvenor Road,

Belfast BT12 6BJ, UK

e-mail: c.patterson@qub.ac.uk

E. Gyürüs $\cdot$ G. Soltész

Department of Paediatrics, Pécs University,

Pécs, Hungary

J. Rosenbauer

Institute of Biometrics and Epidemiology,

German Diabetes Centre, Leibniz Institute for Diabetes

Research at Heinrich Heine University,

Düsseldorf, Germany

O. Cinek

Department of Pediatrics, Second Faculty of Medicine,

Charles University in Prague and University Hospital Motol,

Prague, Czech Republic

\section{A. Neu}

University Children's Hospital,

Tübingen, Germany
Twenty-three centres in 19 countries registered 49,969 new cases of type 1 diabetes in individuals diagnosed before their 15th birthday during the period studied.

Results Ascertainment exceeded $90 \%$ in most registers. During the 20-year period, all but one register showed statistically significant changes in incidence, with rates universally increasing. When estimated separately for the first and second halves of the period, the median rates of increase

\author{
E. Schober \\ Department of Pediatric and Adolescent Medicine, \\ Medical University of Vienna, \\ Vienna, Austria \\ R. C. Parslow \\ Leeds Institute of Genetics, Health and Therapeutics, \\ University of Leeds, \\ Leeds, UK \\ G. Joner \\ Department of Pediatrics, Ullevål University Hospital, \\ Oslo, Norway \\ J. Svensson \\ Department of Paediatrics, University of Copenhagen, \\ Herlev, Denmark \\ C. Castell \\ Department of Health, Government of Catalonia, \\ Barcelona, Spain \\ P. J. Bingley \\ School of Clinical Sciences, University of Bristol, \\ Bristol, UK
}


were similar: 3.4\% per annum and 3.3\% per annum, respectively. However, rates of increase differed significantly between the first half and the second half for nine of the 21 registers with adequate coverage of both periods; five registers showed significantly higher rates of increase in the first half, and four significantly higher rates in the second half. Conclusions/interpretation The incidence rate of childhood type 1 diabetes continues to rise across Europe by an average of approximately 3-4\% per annum, but the increase is not necessarily uniform, showing periods of less rapid and more rapid increase in incidence in some registers. This pattern of change suggests that important risk exposures differ over time in different European countries. Further time trend analysis and comparison of the patterns in defined regions is warranted.

Keywords Epidemiology · Incidence · Temporal change · Trends · Type 1 diabetes

\section{Introduction}

Recent incidence rate trends in childhood type 1 diabetes have been well characterised in publications by the EURODIAB registries in Europe [1] and by the DIAMOND (Diabetes Mondiale) Project Group worldwide [2]. The DIAMOND report described increasing trends in nearly every continent

\author{
E. Schoenle \\ Department of Endocrinology and Diabetology, \\ University Children's Hospital, \\ Zurich, Switzerland \\ P. Jarosz-Chobot \\ Department of Pediatrics, Endocrinology and Diabetes, \\ Medical University of Silesia, \\ Katowice, Poland \\ B. Urbonaité \\ Institute of Endocrinology, \\ Lithuanian University of Health Science, \\ Kaunus, Lithuania \\ U. Rothe \\ Department for Epidemiology and Health Care Research, \\ Technical University of Dresden, \\ Dresden, Germany \\ C. Krzisnik \\ Department of Pediatrics, University Children's Hospital, \\ Ljubljana, Slovenia \\ C. Ionescu-Tirgoviste \\ Nutrition and Metabolic Diseases Clinic, \\ N. Paulescu Institute of Diabetes and Metabolic Diseases, \\ Bucharest, Romania \\ I. Weets \\ Diabetes Research Center, Brussels Free University, \\ Brussels, Belgium
}

in the 1990s, whereas in Europe there was clear evidence that relative increases were highest in central and eastern European countries and in the under-5-year age group during the period 1989-2003.

More recent analyses from Norway [3] and Finland [4] suggest that rates of increase were lower in the 1980s, with a subsequent acceleration in the 1990s. The same pattern is evident in data from Sweden [5], and that analysis additionally raises the possibility that the rapid increase in the $1990 \mathrm{~s}$ may soon be reversed, a reduction in rates having been observed beginning with the 2000 birth cohort.

The EURODIAB group has maintained registers of childhood diabetes in a range of European countries since 1989 using standardised methodology and with validation of completeness of ascertainment, and these observations from Scandinavia led us to compare incidence rates in the first half of the 20-year registration period (1989-1998) with those in the second half (1999-2008).

\section{Methods}

Case inclusion criteria were as previously described for the EURODIAB registers [6]: new diagnoses of type 1 (insulindependent) diabetes mellitus among children aged under 15 years resident in the geographically defined region. The

M. Kocova

Department of Endocrinology and Genetics,

University Children's Hospital,

Skopje, Macedonia

G. Stipancic

Department of Paediatrics,

University Hospital Sestre Milosrdnice,

Zagreb, Croatia

M. Samardzic

Department of Endocrinology and Diabetes,

University Children's Hospital,

Podgorica, Montenegro

C. E. de Beaufort

Department of Paediatric Diabetes and Endocrinology,

Paediatric Clinic,

Luxembourg, Luxembourg

A. Green

Odense Patient data Exploratory Network,

University of Southern Denmark,

Odense, Denmark

G. G. Dahlquist

Department of Clinical Science, University of Umeå,

Umeå, Sweden 
completeness of registration was estimated separately in each of the 10-year periods using capture-recapture methodology [7], which requires that independent primary and secondary sources of ascertainment are available. In most centres, the primary source of ascertainment was through hospital records or notifications by paediatricians and family doctors, whereas secondary sources varied depending on local circumstances and included social insurance schemes, diabetes associations and prescription data.

Annual estimates of the population resident in each centre's geographically defined area were used as denominators for the calculation of directly standardised incidence rates using a standard population consisting of equal numbers of children in each of six subgroups defined by age group (0-4, 5-9 and 10-14 years) and sex.
Poisson regression was used to estimate the trends in incidence rate within centres. For each centre, a model with terms for age group, sex and an age group $\times$ sex interaction was first fitted. Then either a categorical variable representing the 5-year subperiods or a linear term testing for trend across individual years was added to the model to provide comparisons of incidence rates over time that took account of changes in the age structure of the population. For three centres whose registers changed coverage during the period, separate estimates of trend were fitted for each 10-year subperiod, and the two estimates were compared by likelihood ratio test. For the remaining centres, a similar model was fitted but with the added constraint that the fitted lines should meet between 1998 and 1999. Models were fitted using Stata Release 11 (Stata, College Station, TX, USA).

Table 1 Age and sex standardised rates of type 1 diabetes diagnosed before 15 years of age in four five year periods for 23 EURODIAB centres from 19 countries in Europe

\begin{tabular}{|c|c|c|c|c|c|c|c|}
\hline \multirow[t]{2}{*}{ Centre } & \multirow[t]{2}{*}{ Region } & \multirow[t]{2}{*}{ Period } & \multirow{2}{*}{$\begin{array}{l}\text { Number } \\
\text { of cases }\end{array}$} & \multicolumn{4}{|c|}{ Standardised incidence rate per $100,000^{\mathrm{a}}$} \\
\hline & & & & P1 & $\mathrm{P} 2$ & P3 & $\mathrm{P} 4^{\mathrm{b}}$ \\
\hline Austria & Whole nation & 1989-2008 & 3372 & 9.0 & 9.9 & 13.3 & 17.5 \\
\hline Belgium & Antwerp & 1989-2008 & 448 & 10.9 & 12.9 & 15.5 & 15.9 \\
\hline Croatia & Zagreb & 1989-2008 & 339 & 6.7 & 6.4 & 8.2 & 10.4 \\
\hline Czech Republic & Whole nation & 1989-2008 & 4883 & 8.5 & 11.5 & 17.0 & 19.3 \\
\hline \multirow[t]{2}{*}{ Denmark $^{\mathrm{c}}$} & 1) Four counties & $1989-1998$ & 385 & 17.0 & 16.3 & - & - \\
\hline & 2) Whole nation & 1999-2008 & 2402 & - & - & 22.6 & 25.1 \\
\hline Germany & Baden Württemberg & 1989-2007 & 4804 & 11.0 & 13.0 & 15.4 & $21.8^{\mathrm{d}}$ \\
\hline \multirow[t]{2}{*}{ Germany $^{\mathrm{c}}$} & 1) Düsseldorf (seven districts) & 1989-1998 & 595 & 13.3 & 16.8 & - & - \\
\hline & 2) North Rhine-Westphalia & 1999-2008 & 6331 & - & - & 21.3 & 23.7 \\
\hline Germany & Saxony & $1998-2008$ & 921 & - & $11.6^{\mathrm{d}}$ & 15.6 & 20.1 \\
\hline Hungary & 18 counties & 1989-2008 & 3239 & 9.0 & 10.7 & 12.4 & 18.3 \\
\hline Lithuania & Whole nation & 1989-2008 & 1396 & 7.3 & 8.2 & 10.3 & 14.2 \\
\hline Luxembourg & Whole nation & 1989-2008 & 229 & 11.4 & 12.3 & 15.5 & 19.0 \\
\hline Macedonia & Whole nation & 1989-2008 & 447 & 3.2 & 3.9 & 5.6 & 5.8 \\
\hline Montenegro & Whole nation & 1996-2008 & 252 & - & $10.1^{\mathrm{d}}$ & 14.0 & 17.5 \\
\hline \multirow[t]{2}{*}{ Norway $^{c}$} & 1) Eight counties & $1989-2003$ & 1380 & 21.1 & 20.5 & 24.6 & - \\
\hline & 2) Whole nation & 2004-2008 & 1504 & - & - & - & 32.8 \\
\hline Poland & Katowice & 1989-2008 & 1719 & 5.2 & 7.9 & 12.9 & 16.5 \\
\hline Romania & Bucharest & 1989-2008 & 534 & 4.7 & 6.1 & 11.3 & 14.5 \\
\hline Slovenia & Whole nation & 1989-2008 & 715 & 7.9 & 9.2 & 11.1 & 14.6 \\
\hline Spain & Catalonia & 1989-2008 & 2527 & 12.4 & 13.6 & 12.9 & 12.1 \\
\hline Sweden & Stockholm county & 1989-2008 & 1978 & 25.8 & 25.6 & 34.5 & 36.6 \\
\hline Switzerland & Whole nation & $1991-2008$ & 2220 & $8.0^{\mathrm{d}}$ & 8.3 & 11.0 & 13.1 \\
\hline United Kingdom & Northern Ireland & 1989-2008 & 2043 & 20.0 & 24.7 & 29.8 & 33.9 \\
\hline United Kingdom & Oxford & 1989-2008 & 2288 & 17.2 & 21.7 & 24.0 & 25.1 \\
\hline United Kingdom & Yorkshire & 1989-2008 & 3018 & 16.1 & 19.7 & 23.5 & 25.5 \\
\hline
\end{tabular}

${ }^{\mathrm{a}}$ Standard population with six age-sex subgroups of equal size

${ }^{\mathrm{b}}$ Periods denoted P1: 1989-1993, P2: 1994-1998, P3: 1999-2003, P4: 2004-2008

${ }^{\mathrm{c}}$ In three registries, period 2) has extended geographic coverage compared with period 1)

${ }^{\mathrm{d}}$ Rate based on registration data for only part of the period 
The Joinpoint regression program (Version 3.5 - April 2011; Statistical Methodology and Applications Branch and Data Modeling Branch, Surveillance Research Program National Cancer Institute, Bethesda, MD, USA) specifically designed for surveillance of trends in cancer incidence, was also used to see how sensitive conclusions were to the arbitrary division of the period into two 10-year subperiods. Joinpoint provides greater flexibility by accommodating the fitting of two or more linear segments that join at time points that are estimated from the data. The program provides a permutation test to assess the number of linear segments and the times at which they join, while taking into account the multiple testing issues inherent in the approach. A less conservative Bayesian information criterion for model selection was also employed. In order that Joinpoint should mimic as closely as possible the Poisson regression approach, the log-linear model option was chosen, and heteroscedasticity was taken into account by using the standard error of the annual standardised rates.

Further details are provided in the electronic supplementary material $[\mathrm{ESM}]$ Statistical methods.

Table 2 Completeness of ascertainment and estimated annual rates of increase compared in the two 10-year periods 1989-1998 and 1999-2008 for 23 EURODIAB centres

\begin{tabular}{|c|c|c|c|c|}
\hline \multirow[t]{2}{*}{ Centre } & \multirow[t]{2}{*}{ Region } & \multirow{2}{*}{$\begin{array}{l}\text { Completeness of ascertainment, \% } \\
\text { 1989-1998:1999-2008 }\end{array}$} & \multicolumn{2}{|c|}{ Rates of increase per annum, $\%^{\mathrm{a}}(95 \% \mathrm{CI})$} \\
\hline & & & 1989-1998 : 1999-2008 & $p$ value \\
\hline Austria & Whole nation & $99.8: 97.2$ & $3.3(1.8,4.8): 6.1(4.8,7.4)$ & $0.03 *$ \\
\hline Belgium & Antwerp & $98.6: 94.9$ & $3.3(-0.6,7.4): 1.9(-1.6,5.5)$ & 0.68 \\
\hline Croatia & Zagreb & $99.7: 100.0$ & $0.1(-4.3,4.7): 6.8(2.7,11.0)$ & 0.09 \\
\hline Czech Republic & Whole nation & $99.9: 97.4$ & $7.6(6.3,8.8): 3.9(2.9,5.0)$ & $0.001 *$ \\
\hline \multirow[t]{2}{*}{ Denmark $^{\mathrm{b}}$} & 1) Four counties & $99.1:-$ & $0.5(-2.9,4.1)^{\mathrm{c}}:-$ & $0.56^{\mathrm{c}}$ \\
\hline & 2) Whole nation & $-: 99.2^{\mathrm{d}}$ & $-: 1.7(0.2,3.1)^{\mathrm{c}}$ & \\
\hline Germany & Baden Württemberg & $97.2: 100.0$ & $2.9(1.7,4.2): 6.5(5.3,7.7)^{\mathrm{e}}$ & $0.002 *$ \\
\hline \multirow[t]{2}{*}{ Germany $^{\mathrm{b}}$} & 1) Düsseldorf (seven districts) & $94.0:-$ & $6.1(3.2,9.2)^{\mathrm{c}}:-$ & $0.01 * \mathrm{c}$ \\
\hline & 2) North Rhine-Westphalia & $-: 98.6$ & $-: 2.1(1.3,3.0)^{\mathrm{c}}$ & \\
\hline Germany & Saxony & $-: 93.6^{\mathrm{d}}$ & $-: 4.6(2.2,7.1)$ & - \\
\hline Hungary & 18 counties & $97.1: 98.7$ & $3.2(1.8,4.7): 5.8(4.5,7.2)$ & $0.04 *$ \\
\hline Lithuania & Whole nation & $100.0: \mathrm{n} / \mathrm{a}$ & $2.1(-0.1,4.3): 7.2(5.1,9.3)$ & $0.009 *$ \\
\hline Luxembourg & Whole nation & $100.0: 100.0$ & $0.9(-4.7,6.8): 5.8(0.9,10.8)$ & 0.32 \\
\hline Macedonia & Whole nation & $94.9: 100.0$ & $6.4(2.2,10.7): 2.9(-0.5,6.5)$ & 0.33 \\
\hline Montenegro & Whole nation & $100.0: 100.0$ & - : $6.5(1.6,11.7)$ & - \\
\hline \multirow[t]{2}{*}{ Norway ${ }^{b}$} & 1) Eight counties & $100.0:-$ & $-1.2(-3.5,1.1)^{\mathrm{c}}:-$ & $0.42^{\mathrm{c}}$ \\
\hline & 2) Whole nation & $-: 92.0^{\mathrm{d}}$ & $-: 0.5(-3.0,4.2)^{\mathrm{c}, \mathrm{e}}$ & \\
\hline Poland & Katowice & $99.9: \mathrm{n} / \mathrm{a}$ & $10.7(8.3,13.1): 5.5(3.7,7.3)$ & $0.006^{*}$ \\
\hline Romania & Bucharest & $100.0: 100.0$ & $8.0(4.3,12.0): 7.8(4.4,11.2)$ & 0.93 \\
\hline Slovenia & Whole nation & $100.0: 100.0$ & $4.1(1.0,7.2): 3.9(1.1,6.8)$ & 0.96 \\
\hline Spain & Catalonia & $89.4: 97.6$ & $0.9(-0.5,2.4):-1.4(-2.9,0.1)$ & 0.09 \\
\hline Sweden & Stockholm county & $100.0: \mathrm{n} / \mathrm{a}$ & $2.5(0.6,4.5): 2.5(0.9,4.2)$ & 0.66 \\
\hline Switzerland & Whole nation & $91.7^{\mathrm{d}}: 91.3^{\mathrm{d}}$ & $2.1(-0.3,4.5)^{\mathrm{e}}: 5.4(3.8,7.0)$ & 0.07 \\
\hline UK & Northern Ireland & $99.5: 99.5$ & $4.6(2.7,6.5): 2.8(1.2,4.5)$ & 0.27 \\
\hline UK & Oxford & $\mathrm{n} / \mathrm{a}: \mathrm{n} / \mathrm{a}$ & $4.0(2.3,5.8): 0.4(-1.1,2.0)$ & $0.02 *$ \\
\hline UK & Yorkshire & $99.0: 99.6$ & $4.7(3.1,6.3): 1.6(0.3,2.9)$ & $0.02 *$ \\
\hline
\end{tabular}

${ }^{a}$ Derived from Poisson regression model estimates of log-linear trends constraining lines to meet between 1998 and 1999 (see ESM Statistical methods)

${ }^{\mathrm{b}}$ In three registries, period 2) has extended geographic coverage compared with period 1)

${ }^{\mathrm{c}}$ Rates of increase in periods 1) and 2) were estimated and compared without constraining the fitted log-linear trends to meet between 1998 and 1999

${ }^{\mathrm{d}}$ Estimate was obtained independently of the EURODIAB study

${ }^{\mathrm{e}}$ Rate of increase was based on registration data for only part of the period

$* p<0.05$

$\mathrm{n} / \mathrm{a}$, not available 


\section{Results}

Table 1 shows the total numbers of cases registered during the 20-year period 1989-2008 in each of the 23 centres, and the age- and sex-standardised incidence rates in the four 5year subperiods 1989-1993, 1994-1998, 1999-2003 and 2004-2008. The age- and sex-specific incidence rates used in the calculations are available in ESM Table 1. Investigation of changes in incidence during the period was complicated in Denmark and Norway because the registers changed from regional to national coverage, and in Germany because of the extension of the Düsseldorf register to cover the whole North Rhine-Westphalia region. Poisson regression analysis confirmed that there were significant differences in the agestandardised rates between the four periods in all remaining centres with the exception of Catalonia (Spain), and incidence rates were universally observed to increase.

In Table 2 estimates of completeness of ascertainment obtained by the capture-recapture method are presented in the two 10-year periods 1989-1998 and 1999-2008 (for further details, see ESM Table 2). In most centres, greater than $90 \%$ ascertainment was maintained in both periods, with many achieving in excess of $95 \%$ ascertainment. The estimated annual increases (with 95\% confidence intervals) in the first and second 10-year periods are given in the final columns. Comparison of these rates of increase showed a significant acceleration in the rate of increase in four centres (Austria, Germany [Baden Württemberg], Hungary and Lithuania) and a significant deceleration in the rate of increase in five centres (Czech Republic, Germany [Düsseldorf/North Rhine-Westphalia], Poland [Katowice] and the UK [Oxford and Yorkshire]). The median rates of increase over all the centres changed little, from $3.4 \%$ per annum in $1989-1998$ to $3.3 \%$ per annum in $1999-2008$.

Using the default permutation test settings, the Joinpoint program detected significant departures from a uniform loglinear trend with time for two of the largest centres that our analyses had identified - the Czech Republic, with a join between two log-linear segments in 2000, and Germany (Baden Württemberg), with a join in 2002. Using the alternative and less conservative Bayesian Information Criterion settings, the program detected departures from uniform loglinear trend with time in a further five of the centres identified by our analysis - Austria, Hungary, Lithuania, Poland (Katowice) and the UK (Yorkshire).

\section{Discussion}

The incidence rate of childhood type 1 diabetes continues to rise across Europe by approximately 3-4\% per annum, but the increase is not necessarily uniform, with periods of less rapid and more rapid increase in incidence occurring in many registers. Although such patterns of change in incidence rate have previously been described in Scandinavian countries, our analysis suggests that the same phenomenon is also occurring in other parts of Europe.

Although our analysis may be criticised for comparing two arbitrarily selected 10-year periods, the finding of significant differences in the rates of increase in nine of the 21 centres for which the comparison was possible does suggest that these changes in rate are not an artefact, particularly since the completeness of registration was uniformly high in most of these centres. The Joinpoint program provided broad confirmation of our findings, but only when the less conservative Bayesian Information Criterion was used for model selection.

The possibility that changes in trends are affecting different age groups at different times cannot be ruled out. Use of age-period-cohort models has the potential to address this issue, but long-term data over broad age ranges are necessary for this technique to provide useful conclusions [8], and there are well-recognised difficulties in separating period and cohort effects when the predominant pattern of change is one of a log-linear increase [9].

Given the changing trends over time observed within individual centres in our analysis, forecasting future numbers of cases of type 1 diabetes in children by extrapolating past trends in a single centre or country could be misleading, and a better general strategy may be to derive trend estimates from groups of geographically adjacent countries with broadly similar incidence rates when attempting such extrapolations [1].

Our findings suggest that important environmental risk exposures are changing over time in different ways across European countries. Further time trend analysis and comparison of the patterns in different regions within Europe are warranted.

Acknowledgements The authors acknowledge the Austrian Diabetes Incidence Study Group, the Belgian Diabetes Registry (fellowship for I. Weets from the Belgian Fund for Scientific Research), the Danish Study Group of Diabetes in Childhood, the Baden-Württemberg Diabetes Incidence Registry (DIARY), the German Paediatric Surveillance Unit, Düsseldorf University and DPV Science Initiative, Ulm University, the German Competence Network Diabetes Mellitus (Federal Ministry of Education and Research, support codes 01GI0802, 01GI0859), the Saxonian Childhood Diabetes Register Group, the Hungarian Childhood Diabetes Epidemiology Group, the Norwegian Childhood Diabetes Study Group (supported by the South-Eastern Norway Regional Health Authority), the Catalan Epidemiology Type 1 Diabetes Study Group, the Swedish Childhood Diabetes Study Group (supported by the Swedish Research Council, Project number 07531), the Northern Ireland Childhood Diabetes Group, the Bart's-Oxford Study Group (supported by Diabetes UK) and the Yorkshire Register of Diabetes in Children and Young People (supported by the UK Healthcare Quality Improvement Partnership). The collaboration was supported in part by European Community Concerted Action Program grants (BMH1-CT92-0043, BMH4CT96-0577 and IC20-CT96-0070).

Duality of interest The authors declare that there is no duality of interest associated with this manuscript. 
Contribution statement CCP has coordinated the group since 2010, undertook the statistical analysis and wrote a first draft of the report. EG maintained contact with the study centres and assembled and validated the data for analysis. AG set up the collaboration and coordinated the group until 1998 and together with GGD established the registration methodology. GS coordinated the group from 1998 to 2009. Remaining authors established and/or maintained the registration process in the different centres, and were thereby responsible for data collection. They also validated the ascertainment level. All authors commented on a draft of the report and approved the final manuscript.

\section{References}

1. Patterson CC, Dahlquist GG, Gyürüs E, Green A, Soltész G, the EURODIAB Study Group (2009) Incidence trends for childhood type 1 diabetes in Europe during 1989-2003 and predicted new cases 200520: a multicentre prospective registration study. Lancet 373:2027-2033

2. The DIAMOND Project Group (2006) Incidence and trends of childhood type 1 diabetes worldwide 1990-1999. Diabet Med 23:857-866

3. Aamodt G, Stene LC, Njølstad PR, Søvik O, Joner G, Norwegian Childhood Diabetes Study Group (2007) Spatiotemporal trends and age-period-cohort modeling of the incidence of type 1 diabetes among children aged $<15$ years in Norway 1973-1982 and 1989-2003. Diabetes Care 30:884-889

4. Harjutsalo V, Lena Sjöberg S, Tuomilehto J (2008) Time trends in the incidence of type 1 diabetes in Finnish children: a cohort study. Lancet 371:1777-1782

5. Berhan Y, Waernbaum I, Lind T, Möllsten A, Dahlquist G, Swedish Childhood Diabetes Study Group (2011) Thirty years of prospective nationwide incidence of childhood type 1 diabetes: the accelerating increase by time tends to level off in Sweden. Diabetes 60:577-581

6. Green A, Gale EAM, Patterson CC (1992) Incidence of childhoodonset insulin-dependent diabetes mellitus: the EURODIAB ACE study. Lancet 339:905-909

7. Bishop YMM, Fienberg SE, Holland PW (1974) Discrete multivariate analysis: theory and practice. MIT Press, Cambridge, pp 231-237

8. Dahlquist GG, Nystrom L, Patterson CC, the Swedish Childhood Diabetes Study Group and the Diabetes Incidence in Sweden Study Group (2011) Incidence of type 1 diabetes in Sweden among individuals aged 0-34 years, 1983-2007: an analysis of time trends. Diabetes Care 34:1754-1759

9. Clayton D, Schifflers E (1987) Models for temporal variations in cancer rates II: age-period-cohort models. Stat Med 6:469-481 